\title{
THE ROLE OF AWARENESS IN SECOND LANGUAGE DEVELOPMENT
}

\author{
Fahriany \\ UIN Syarif Hidayatullah Jakarta \\ fahriany@ymail.com
}

\begin{abstract}
Cognitive psychology and cognitive science appear to agree that attention to stimuli is needed for long-term memory storage and that little, if any, learning can take place without attention. One strand of psycholinguistic research that has drawn quite a lot of interest, both from a theoretical and empirical perspective, is the role awareness plays in second language acquisition (SLA). To promote a further understanding of the role of awareness may potentially contribute to L2 development. This article will briefly describe current theoretical approaches to the role of awareness in language learning, review recent studies that have employed verbal reports to investigate the effects of awareness on L2 development, and provide, based on the review, some awareness-raising pedagogical tasks for the L2 classroom setting.
\end{abstract}

Keywords: attention, awareness, detection, feedback, L2 development

Psycholinguistic research in second/foreign language (L2) learning or acquisition has undoubtedly become one of the major components of many current teacher education programs (Bardovi-Harlig \& Hartford, 1997; Leow, 1994a, 1994b, 1995a, 1995b). One strand of research within this field that has drawn quite a lot of interest, both from a theoretical and empirical perspective, is the role awareness plays in second language acquisition (SLA). To promote a further understanding of the role of awareness may potentially contribute to L2 development. I will (1) briefly describe current theoretical approaches to the role of awareness in language learning, (2) review recent studies that have employed verbal reports to investigate the effects of awareness on L2 development, and (3) provide, based on the review, some awareness-raising pedagogical tasks for the L2 classroom setting.

\section{Theoretical Underpinnings}

The role of awareness or lack there of in L2 learning is subsumed in several major theoretical approaches to the role of attention in SLA (e.g., Robinson, 1995a; Schmidt, 1990, 1993, 1994, 1995, 2001; Tomlin \& Villa, 1994) mainly in the formal classroom setting. Many theories of SLA posit, directly or indirectly, some role for attention, but the construct is especially emphasized in cognitivist accounts, where it is argued that "attention appears necessary for understanding nearly every aspect of second and foreign language learning" (Schmidt, 2001:6). Indeed, both cognitive psychology and cognitive science appear to agree that attention to stimuli is needed for long-term memory storage and that little, if any, learning can take place without attention (e.g., Carlson \& Dulany, 1985; Carr \& Curran, 1994; Nissen \& Bullemer, 1987; Posner, 1992; Reber, 1967, 1976, 1989, 1993).

There are three major approaches to the roles of attention and awareness in SLA, namely, Tomlin and Villa's (1994) functional model of input processing in SLA, Schmidt's (1990 and elsewhere) noticing hypothesis, and Robinson's 
(1995a) model of the relationship between attention and memory.

Tomlin and Villa's Functional Model of Input Processing in SLA

Drawing on the work of Posner (1992) in cognitive science, Tomlin \& Villa (1994) propose a functionally-based, fine-grained analysis of attention. In their models, attention has three components with neurological correlates: (1) alertness, which is an overall readiness to deal with incoming stimuli, (2) orientation, which is the direction of attentional resources to a certain type of stimuli, and (3) detection, which is the cognitive registration of stimuli. According to Tomlin \& Villa (1994), it is only the attentional function of detection that is necessary for further processing of input and subsequent learning to take place. The other two components (alertness and orientation) can separately or together enhance the chances that detection will occur, but neither is necessary. In addition, detection does not imply awareness given that, according to Tomlin \& Villa (1994), a learner may detect some linguistic information in the input, processes it but does not need to be aware of doing so.

\section{Schmidt's Noticing Hypothesis}

In direct contrast to Tomlin \& Villa's (1994) postulation that awareness is not necessary for learning, it is more widely accepted in SLA that the absence of awareness during input processing may only result in short-term memory, which may then not be further processed for learning to take place. According to Schmidt's (1990 and elsewhere) noticing hypothesis, attention controls access to awareness and is responsible for noticing, which is "the necessary and sufficient condition for the conversion of input into intake ${ }^{1 "}$ (Schmidt, 1993:209). He views attention as being isomorphic with awareness and rejects the notion of learning without awareness. Furthermore, Schmidt proposes that, in addition to noticing, that is, awareness at the level of noticing, there is another higher level of awareness, which he refers to as awareness at the level of understanding. This level of awareness is characterized by learners' ability to analyze, compare, and test hypotheses and leads to deeper learning marked by restructuring and system learning. On the other hand, awareness at the level of noticing leads to mere intake of linguistic information.

\section{Robinson's Model of the Relationship between Attention and Memory}

A third model of attention proposed in SLA is that of Robinson (1995a) who reconciles Tomlin \& Villa's (1994) notion of detection (which does not involve awareness) and Schmidt's (1990 and elsewhere) notion of noticing (which does involve awareness). Robinson's model strategically places detection at an earlier stage in the process in relation to noticing and input processing. Noticing, according to Robinson's model, is "detection plus rehearsal in shortterm memory, prior to encoding in long-term memory" (Robinson, 1995a:296). Noticing, like in Schmidt's hypothesis, does involve awareness, and is crucial for learning to take place. Robinson's model, then, acknowledges Tomlin and Villa's notion of detection in language learning but reduces its impact on learning by relegating it to an earlier stage in the learning process before Schmidt's notion of noticing, which he places at a later and more crucial stage of input processing.

\section{Awareness and Learning}

As can be seen from the different theoretical models of attention, while the facilitative role of attention in L2 development is generally accepted, the role of awareness in language learning is not without debate. Specifically, Schmidt's noticing hypothesis and Robinson's model of the relationship between attention and memory posit a crucial role for awareness, whereas Tomlin \& Villa's functional model of input processing does not. But what is awareness and how has it been defined in SLA? Tomlin \& Villa (1994:193) define awareness as "a particular state of mind in which an individual has undergone a specific subjective experience of some cognitive content 
or external stimulus". Awareness, according to Allport (1988), is demonstrated through a) some resulting behavioral or cognitive change, $b$ ) a report of the experience, or c) metalinguistic description of an underlying rule. While it is accepted that attentional resources may be allocated to a specific linguistic item in the input, the question that remains unanswered is whether the presence of learner awareness is required for the grammatical information to be processed further by the learner. Not surprisingly, several researchers have supported a dissociation between learning and awareness (e.g., Carr \& Curran, 1994; Curran \& Keele, 1994; Hardcastle, 1993; Tomlin \& Villa, 1994; Velmans, 1991) while others have rejected this dissociation (Leow, 2000; Robinson, 1995a; Schmidt, 1990 and elsewhere).

\section{Pedagogical Tasks}

The most important implication for the classroom setting derived from studies premised on attention and awareness in SLA is that learner attention to targeted forms in the L2 input is minimally a prerequisite for subsequent processing to take place. However, more attention to targeted forms may not be sufficient to promote robust processing and potential internalization of the L2 linguistic information. Given the overall beneficial effects of tasks (premised on the features task-essentialness and feedback) that raise learner awareness and are theoretically and empirically supported, it is recommended that pedagogical tasks or activities be designed to do the following: (1) explicitly draw learners' attention to targeted forms or structures and (2) encourage meaningful interaction with the input through the creation of explicit conditions, exposure, or instruction to promote the allocation of more attentional resources to notice such forms. In other words, these are tasks in which learners need to notice or be aware of the targeted form or structure in order to successfully complete the task.

Awareness-raising tasks are easily designed via problem-solving tasks or activities, which, in addition to the inherent interest in solving the problem, create the opportunity to use the L2 from a student-centered and creative way. Pedagogical tasks, which include carefully designed crossword puzzles, games, or selfdiscovery grammatical tasks, may be either classroom-based or non-classroom based. Since raising students' awareness of L2 linguistic features is more an internal than external process, it is suggested that these tasks be performed outside the classroom with the opportunity to extend the tasks into the classroom setting. The ideal platform for the creation and use of such awareness-raising tasks or activities is via the computer, and the targeted forms or structures may be the more problematic ones in the L2.

It is important to note that this article does not presume that these kinds of computerized awareness-raising tasks constitute the only pedagogical avenue for successful L2 development in the classroom setting. On the contrary, these computerized tasks only address one aspect of the learning and teaching processes. Indeed, the ideal setting for these computerized tasks is outside the classroom and should be viewed as ancillary tools to prepare students for communicative practice in the actual classroom setting, powered by the important role of the teacher.

\section{CONCLUSION}

This article has presented a concise overview of the theoretical and methodological issues surrounding the role of awareness in adult second/foreign language behavior and learning, and provided a brief report of current empirical studies that have employed verbal reports to investigate this role in L2 development in the L2 classroom. The overall findings appear to indicate facilitative effects of awareness on adult L2 learners' subsequent processing, intake, and learning of targeted L2 forms or structures embedded in the L2 data, providing empirical support for the facilitative role of awareness in SLA. Pedagogical tasks, premised on taskessentialness and concurrent feedback and 
designed to raise learner awareness of linguistic information in the L2 input, are recommended

\section{REFERENCES}

Carr, T.H., \& Curran, T. (1994). Cognitive Factors in Learning about Structured Sequences: Applications to Syntax. Studies in Second Language Acquisition, 75 (2), 205-230.

Leow, R.P. (2000). A Study of the Role of Awareness in Foreign Language Behavior: Aware Versus Unaware Learners. Studies in Second Language Acquisition, 22 (4), 557-584.

Leow, R.P. (2001). Attention, Awareness, and Foreign Language Behavior. Language Learning, 51 (1), 113-155.

Robinson, P. (1997a). Generalizability and Automaticity of Second Language Learning Under Implicit, Incidental, Enhanced, and Instructed Conditions. Studies in Second Language Acquisition, 19 (2), 223-247.

Robinson, P. (1997b). Individual Differences and the Fundamental Similarity of Implicit and Explicit Adult Second Language Learning. Language Learning, 47 (1), 45-99.

Rosa, E., \& Leow, R.P. (2004a). Awareness, Different Learning Conditions, and L2 Development. Applied Psycholinguistics, 25 (2), 269-292.

Rosa, E., \& Leow, R.P. (2004b). Computerized Task-Based Exposure, Explicitness, Type of Feedback, and Spanish L2 Development. Modern Language Journal, 88 (2), 192-216. for use as ancillary tools to promote robust learning of problematic forms or structures in the L2.

Schmidt, R. (1995). Consciousness and Foreign Language Learning: A Tutorial on the Role of Attention and Awareness in Learning. In R. W. Schmidt (Ed.), Attention and Awareness in Foreign Language Learning. Honolulu, HI: University of Hawai'i.

Schmidt, R. (2001). Attention. In P. Robinson (Ed.), Cognition and Second Language Instruction (pp. 3-32). Cambridge: Cambridge University Press.

Schmidt, R., \& Frota, S. (1986). Developing Basic Conversational Ability in a Second Language. In R. Day (Ed.), Talking to learn (pp. 237-326). Rowley, MA: Newbury House.

Shanks, D.R., \&St. John, M.F. (1994). Characteristics of Dissociable Human Learning Systems. Behavioral and Brain Sciences, 17, 367447.

Tomlin, R.S., \& Villa, V. (1994). Attention in Cognitive Science and Second Language Acquisition. Studies in Second Language Acquisition, 16 (2), 183-203.

Velmans, M. (1991). Is Human Information Processing Conscious? Behavioral and Brain Sciences, 14, 651-669.

Williams, J.N. (2004). Implicit Learning of FormMeaning Connections. In J. Williams, B. VanPatten, S. Rott \& M. Overstreet (Eds.), Form-Meaning Connections in Second Language Acquisition (pp. 203218). Mahwah, NJ: Lawrence Erlbaum Associates. 